Jurnal Ilmiah Matematika dan Pendidikan Matematika (JMP)

Vol. 12 No. 2, Desember 2020, hal. 29-41

ISSN (Cetak) : 2085-1456; ISSN (Online) : 2550-0422

\title{
ANALISIS FAKTOR-FAKTOR YANG BERPENGARUH TERHADAP KINERJA PEGAWAI PT. KERETA API INDONESIA (PERSERO) DAOP 5 PURWOKERTO DENGAN PARTIAL LEAST SQUARE
}

\author{
Jajang \\ Jurusan Matematika, Universitas Jenderal Soedirman \\ jajang@unsoed.ac.id \\ Supriyanto \\ Jurusan Matematika, Universitas Jenderal Soedirman \\ Dimas Eka Putra \\ Jurusan Matematika, Universitas Jenderal Soedirman
}

\begin{abstract}
In this research, PLS method is applied to analyze which factor are affect employee performance in PT. Kereta Api Indonesia (Persero) DAOP 5 Purwokerto based on employee performance, work motivation, leadership, training, work enviroment and corporate culture through the indicator which are then analyzed. From analysis using a PLS method with 6 variables of research, it was found that R-square value work of motivation variables of 77,00\% with good assessments defined by construct variable of leadership, training, work enviroment and corporate culture while another $23 \%$ is described by other variables outside this research. The value of $R$-square on employee performance variables of 66,00\% with good enough assessment criteria described by the work of motivation, whereas another $34 \%$ is described by other variables outside this research model.
\end{abstract}

Keywords: partial least square, employee performance, PT. Kereta Api Indonesia, DAOP 5 Purwokerto.

\begin{abstract}
ABSTRAK. Pada penelitian ini, metode PLS diaplikasikan untuk menganalisis faktorfaktor yang mempengaruhi kinerja pegawai PT. Kereta Api Indonesia (Persero) DAOP 5 Purwokerto berdasarkan kinerja pegawai, motivasi kerja, kepemimpinan, pelatihan, lingkungan kerja dan budaya perusahaan melalui beberapa indikator yang kemudian dianalisis. Dari hasil analisis menggunakan metode PLS dengan 6 variabel penelitian, diperoleh bahwa nilai $R$-square untuk variabel motivasi kerja sebesar $77,00 \%$ dengan kriteria penilaian bagus yang dijelaskan oleh variabel konstruk kepemimpinan, pelatihan, lingkungan kerja, dan budaya perusahaan, sedangkan 23,00\% lainnya dijelaskan oleh variabel diluar model penelitian ini. Nilai $R$-square untuk variabel kinerja pegawai sebesar $66,00 \%$ dengan kriteria penilaian cukup bagus yang dijelaskan oleh motivasi kerja, sedangkan 34\% lainnya dijelaskan oleh variabel diluar model penelitian ini.
\end{abstract}

Kata Kunci: DAOP 5 Purwokerto, kinerja pegawai, partial least square, PT. Kereta Api Indonesia. 


\section{PENDAHULUAN}

Suatu perusahaan perlu mengadakan penilaian kinerja pegawai untuk menilai pencapaian kinerja pegawai dalam melaksanakan tugas. Menurut Bernadin dan Russel (2000) kinerja adalah outcome yang dihasilkan dari fungsi suatu pekerjaan tertentu atau kegiatan selama satu periode tertentu. Penilaian kinerja dilaksanakan berdasarkan bentuk dan isi pekerjaan yang diberikan kepada pegawai untuk mencapai setiap aspek dari pekerjaan pegawai (Rivai, dkk., 2011). Sumber daya manusia merupakan hal penting penyedia jasa transportasi. Seiring perkembangan teknologi transportasi dan juga fasilitas-fasilitas transportasi secara pesat. Begitu juga dengan perusahaan penyedia jasa transportasi darat pun mulai berkembang dan bermunculan diiringi dengan teknologi yang menunjang fasilitas, termasuk PT. Kereta Api Indonesia.

Bagi instansi penyedia transportasi darat seperti PT. Kereta Api Indonesia (Persero), peningkatan kualitas pelayanan adalah mempunyai pengaruh besar terhadap keputusan penggunaan yang ditawarkan. Sebagai perusahaan yang menyediakan jasa transportasi darat, perbaikan kualitas pelayanan adalah menjadi prioritas utama agar mampu memenuhi kebutuhan pasar.

Berdasarkan uraian di atas, perlu kajian terkait faktor-faktor yang mempengaruhi kinerja pegawai PT. Kereta Api Indonesia (Persero) DAOP 5 Purwokerto. Fokus masalah dalam penelitian ini adalah analisis faktor-faktor mana saja yang berpengaruh terhadap kinerja pegawai dan bagaimana pemodelan kinerja pegawai PT. Kereta Api Indonesia (Persero) DAOP 5 Purwokerto. Penelitian kepuasan kinerja pegawai di lingkungan PT. Kereta Api Indonesia (Persero) telah dilakukan Antaka (2018) menggunakan metode regresi linier. Metode yang digunakan dalam penelitian ini terdiri dari model regresi dan faktor analisis. Analisis faktor adalah metode untuk menganalisis observasi dari sisi interkorelasinya (Fruchter, 1954). Analisis faktor dikategorikan menjadi exploratory dan confirmatory (Hair, dkk., 2010). Yang termasuk dalam kategori EFA adalah analisis cluster dan analisis faktor, sedangkan yang termasuk dalam kategori CFA adalah Structural Equation Model (SEM), yang salah satunya adalah Partial Least Square (PLS) (Hair, dkk., 2010). Dalam PLS dapat 
dilakukan pengujian validitas dan reliabilitas melalui model Pengukuran dan uji kausalitas melalui model struktural. (Abdillah, 2015). Model PLS juga telah banyak diterapkan, diantaranya oleh Putri (2018), Jihan (2010) dalam bidang Kesehatan.

\section{METODE PENELITIAN}

\subsection{Langkah-langkah Penelitian}

Langkah-langkah penelitian yang dilakukan antara lain koleksi data melalui kuisioner dan wawancara, uji validitas dan relibilitas, eksplorasi data hasil wawancara, pembuatan model dan terakhir interpretasi model.

\subsection{Data Penelitian}

Data yang digunakan dalam penelitian ini merupakan sampel data dari hasil survei kuesioner yang disebar disetiap unit kerja. Kuesioner tersebut berisi beberapa pernyataan yang berhubungan dengan variabel penelitian. Terdapat alternatif jawaban yang diberikan untuk mengisi pernyataan kuesioner dengan skala likert, yaitu: Sangat Tidak Setuju (STS) bernilai 1; Tidak Setuju (TS) bernilai 2; Ragu-Ragu (RR) bernilai 3; Setuju (S) bernilai 4; dan Sangat Setuju (SS) bernilai 5 .

\subsection{Metode Penelitian}

Metode penelitian yang digunakan dalam analisis kepuasan ini adalah model Partial Least Square (PLS). Komponen-komponen terdiri dari Variabel laten dan variabel teramati. Menurut Kuntoro (2006), variabel laten terbagi menjadi variabel laten endogen , $\eta$ (small eta) dan variabel laten eksogen $\xi$ (small $k s i)$. Variabel teramati atau variabel manifes adalah variabel yang dapat diamati yang diukur secara empiris. Variabel manifest terbagi variabel manifes eksogen, $X_{i}$ dan variabel manifes endogen $Y_{i}$, (Kuntoro, 2006). Model PLS terdiri dari model struktural dan model pengukuran.

Model struktural adalah

$$
\boldsymbol{\eta}=\boldsymbol{\beta} \boldsymbol{\eta}+\Gamma \xi+\zeta
$$






dengan $\boldsymbol{\eta}$ adalah eta adalah variabel $\mathrm{Y}$ atau variabel laten endogen (mx1), $\boldsymbol{\xi}$ adalah variabel $\mathrm{X}$ atau variabel laten eksogen $(\mathrm{mxm}), \boldsymbol{\beta}$ koefisien pengaruh antara variabel endogen dengan variabel endogen $(\mathrm{mx} 1)$, $\Gamma$ koefisien pengaruh antara variabel endogen dengan variabel eksogen $(m \times n), \zeta$ kesalahan (error) pengukuran pada variabel laten endogen (nx1), $\boldsymbol{m}$ dan $\boldsymbol{n}$ berturut turut adalah banyaknya variabel laten endogen dan variabel indikator.

Model pengukuran terdiri dari model pengukuran variabel endogen dan eksogen. Model pengukuran variabel endogen adalah

$$
\begin{gathered}
\overrightarrow{\boldsymbol{y}}= \\
{\left[\begin{array}{c}
y_{1} \\
y_{2} \\
\vdots \\
y_{q}
\end{array}\right]=\left[\begin{array}{cccc}
\lambda_{y_{11}} & \lambda_{y_{12}} & \cdots & \lambda_{y_{1 m}} \\
\lambda_{y_{21}} & \lambda_{y_{22}} & \cdots & \lambda_{y_{2 m}} \\
\vdots & \vdots & \ddots & \vdots \\
\lambda_{y_{q 1}} & \lambda_{y_{q 2}} & \cdots & \lambda_{y_{q m}}
\end{array}\right]\left[\begin{array}{c}
\eta_{1} \\
\eta_{2} \\
\vdots \\
\eta_{m}
\end{array}\right]+\left[\begin{array}{c}
\varepsilon_{1} \\
\varepsilon_{2} \\
\vdots \\
\varepsilon_{q}
\end{array}\right],}
\end{gathered}
$$

dengan $\boldsymbol{y}$ adalah vektor variabel manifest endogen (qx1), $\boldsymbol{\Lambda}_{\boldsymbol{y}}$ adalah matriks koefisien pengukuran (loading factor) $((q \times m)$, $\boldsymbol{\eta}$ adalah vektor error pengukuran $(m \times 1), \boldsymbol{\varepsilon}$ adalah vector sisaan acak. $\boldsymbol{q}$ adalah banyaknya indikator variabel endogen. Model pengukuran variabel elsogen adalah:

$$
\begin{gathered}
\overrightarrow{\boldsymbol{x}}= \\
{\left[\begin{array}{c}
x_{1} \\
x_{2} \\
\vdots \\
x_{p}
\end{array}\right]=\left[\begin{array}{cccc}
\lambda_{x_{11}} & \lambda_{x_{12}} & \cdots & \lambda_{x_{1 n}} \\
\lambda_{x_{21}} & \lambda_{x_{22}} & \cdots & \lambda_{x_{2 n}} \\
\vdots & \vdots & \ddots & \vdots \\
\lambda_{x_{p 1}} & \lambda_{x_{p 2}} & \cdots & \lambda_{x_{p n}}
\end{array}\right]\left[\begin{array}{c}
\xi_{1} \\
\xi_{2} \\
\vdots \\
\xi_{n}
\end{array}\right]+\left[\begin{array}{c}
\delta_{1} \\
\delta_{2} \\
\vdots \\
\delta_{p}
\end{array}\right],}
\end{gathered}
$$

dengan $\boldsymbol{x}$ adalah vektor variabel manifest eksogen (px1), $\boldsymbol{\Lambda}_{\boldsymbol{x}}$ adalah matriks koefisien pengukuran (loading factor)(pxn), $\xi$ adalah adalah variabel laten eksogen, $\delta$ adalah vektor error pengukuran (nx1), padalah banyaknya indikator variabel eksogen. Permasalahan utama dalam PLS adalah bagaimana menentukan variabel laten dan loading factor. Berikut adalah algoritma untuk menentukan komponen tersebut. 


\section{Algoritma PLS tahap 1.}

Untuk perhitungan bobot yang terdiri dari estimasi model pengukuran dan estimasi model struktural. Estimasi model pengukuran adalah $\hat{\xi}_{j}=y_{j}=$ $\sum_{k=1}^{K_{j}} \widetilde{w}_{j k} x_{j k}$ dan estimasi model struktural $z_{j} \propto \sum_{\xi_{j} \text { dihubungkan pada } \xi_{j}}^{J} e_{j i} y_{i}$, dengan $e_{j i}=\operatorname{reg}\left(y_{j}, y_{i}\right)$ dan $y_{j}=\sum_{i=1, i \neq j}^{J} e_{j i} y_{i}$ koefisien $e_{j i}$ dalam persamaan regresi dari $y_{i}$ pada $y_{j}$. Setelah itu pembobot diupdate untuk mendapatkan nilai yang optimal, melalui $w_{j k}=\lambda_{j k}=\left(z_{j}^{T} z_{j}\right)^{-1} z_{j}^{T} x_{j k}=\operatorname{reg}\left(x_{j k}, z_{j}\right)$ dan dan bobot untuk variabel laten endogen adalah: $w_{j k}=\lambda_{j k}=\left(z_{j}^{T} z_{j}\right)^{-1} z_{j}^{T} y_{j k}=$ $\operatorname{reg}\left(y_{j k}, z_{j}\right)$.

\section{Algoritma PLS Tahap 2.}

Algoritma PLS tahap 2 adalah proses perhitungan estimasi untuk koefisien jalur $\left(\hat{\gamma}_{j i}\right)$ dan perhitungan loading $\left(\hat{\lambda}_{j k}\right)$ sesuai dengan model pengukuran dan model struktural, yaitu $y_{j}=\sum_{i=1}^{I_{j}} \hat{\gamma}_{j i} y_{i}, \hat{\gamma}_{j i}=\left(y_{i}^{\prime} y_{i}\right)^{-1} y_{i}^{T} y_{j}$, dan selanjutnya diperoleh $x_{j k}=\hat{\lambda}_{j k} z_{j}, \quad \hat{\lambda}_{j k}=\left(z_{j}{ }^{T} z_{j}\right)^{-1} z_{j}{ }^{T} x_{j k}=w_{j k}, \quad$ sehingga $z_{j}=\sum_{k=1}^{K_{j}} \hat{\lambda}_{j k} x_{j k}, \quad \hat{m}_{j}=$ $\sum_{k=1}^{K_{j}} \widetilde{w}_{j k} \tilde{x}_{j k}, \operatorname{dan} \hat{\xi}_{j}=y_{j}+\widehat{m}_{j}$.

\section{HASIL DAN PEMBAHASAN}

\subsection{Menyusun Model Konseptual Berbasis Teori}

Model konseptual pada penelitian ini mencakup dua variabel laten endogen (motivasi Kerja $\left(\eta_{1}\right)$, kinerja Pegawai $\left(\eta_{2}\right)$ ), variabel laten eksogen kepemimpinan $\left(\xi_{1}\right)$, Pelatihan $\left(\xi_{2}\right)$, Lingkungan Kerja $\left(\xi_{3}\right)$, dan Budaya Perusahaan $\left(\xi_{4}\right)$. Variabel laten endogen dan eksogen masing-masing terdiri dari 7 variabel indikator. Model konseptual penelitian yang dirancang adalah sebagai berikut.

\subsubsection{Merancang Outer Model (Model Pengukuran)}

Model pengukuran terdiri dari model laten endogen dan eksogen. 

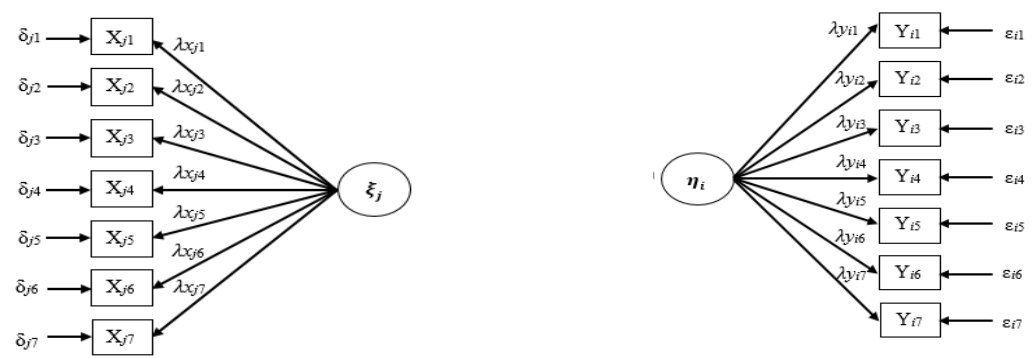

Gambar 1. Model Pengukuran Laten Eksogen dan Endogen

\subsubsection{Merancang Inner Model (Model Struktural)}

Model struktural dalam penelitian ini adalah sebagai berikut:

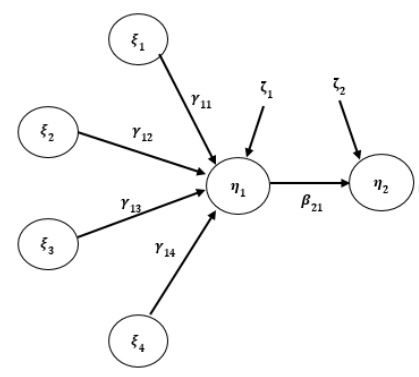

Gambar 2. Model Struktural Antara Variabel Laten Eksogen dan Endogen

\subsection{Mengkonstruksi Diagram Jalur (Path Diagram)}

Berdasarkan kerangka konseptual model penelitian yang diperoleh diperoleh kontruksi diagram jalur (path diagram) yang disajikan pada Gambar 3.

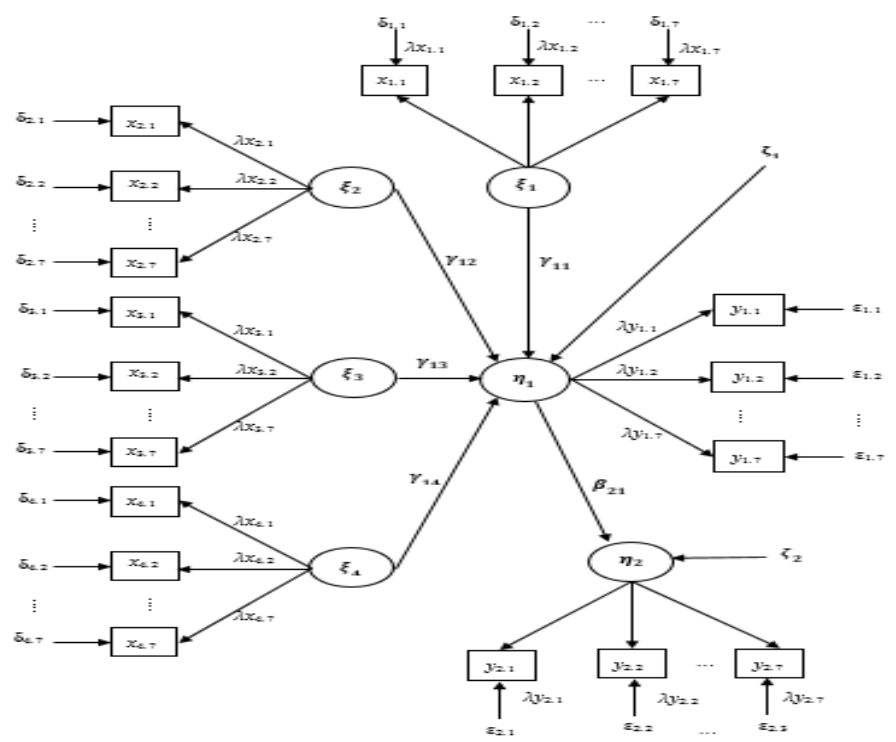

Gambar 3 Konstruksi Diagram Jalur (Path Diagram) 


\subsection{Mengkonversi Diagram Jalur ke dalam Sistem Persamaan}

Konversi model pengukuran dan model struktural ke dalam bentuk model sederhana diperoleh

$$
\begin{aligned}
x_{j .1 . n} & =\Lambda_{x_{j .1 . n}} \xi_{j .1}+\delta_{j .1 . n} & & y_{i .1 . n}=\Lambda_{y_{i .1 . n}} \eta_{i .1}+\varepsilon_{i .1 . n} \\
x_{j .2 . n} & =\Lambda_{x_{j .2 . n}} \xi_{j .2}+\delta_{j .2 . n} & & y_{i .2 . n}=\Lambda_{y_{i .2 . n}} \eta_{i .2}+\varepsilon_{i .2 . n} \\
x_{j .3 . n} & =\Lambda_{x_{j .3 . n}} \xi_{j .3}+\delta_{j .3 . n} & & y_{i .3 . n}=\Lambda_{y_{i .3 . n}} \eta_{i .3}+\varepsilon_{i .3 . n} \\
x_{j .4 . n} & =\Lambda_{x_{j .4 . n}} \xi_{j .4}+\delta_{j .4 . n} & & y_{i .4 . n}=\Lambda_{y_{i .4 . n}} \eta_{i .4}+\varepsilon_{i .4 . n} \\
x_{j .5 . n} & =\Lambda_{x_{j .5 . n}} \xi_{j .5}+\delta_{j .5 . n} & & y_{i .5 . n}=\Lambda_{y_{i .5 n}} \eta_{i .5}+\varepsilon_{i .5 . n} \\
x_{j .6 . n} & =\Lambda_{x_{j .6 n}} \xi_{j .6}+\delta_{j .6 . n} & y_{i .6 . n} & =\Lambda_{y_{i .6 n}} \eta_{i .6}+\varepsilon_{i .6 . n} \\
x_{j .7 . n} & =\Lambda_{x_{j .7 . n}} \xi_{j .7}+\delta_{j .7 . n} & y_{i .7 . n} & =\Lambda_{y_{i .7 . n}} \eta_{i .7}+\varepsilon_{i .7 . n}
\end{aligned}
$$

Model struktural yang diperoleh adalah

$\eta_{1}=\gamma_{11} \xi_{1}+\gamma_{12} \xi_{2}+\gamma_{13} \xi_{3}+\gamma_{14} \xi_{4}+\zeta_{1}$ dan $\eta_{2}=\beta_{21} \eta_{1}+\zeta_{2}$.

\subsection{Estimasi Parameter Partial Least Square}

\section{a. Koefisien Model Pengukuran Variabel Laten Eksogen dan Endogen}

Tabel 1 Koefisien Nilai loading Variabel Laten Eksogen dan Endogen

\begin{tabular}{|c|c|c|}
\hline Motivasi Kerja & Kinerja Pegawai & Kepemimpinan \\
\hline$\lambda y_{1.1}=0,802$ & $\lambda y_{2.1}=0,687$ & $\lambda x_{1.1}=0,869$ \\
$\lambda y_{1.2}=0,827$ & $\lambda y_{2.2}=0,727$ & $\lambda x_{1.2}=0,881$ \\
$\lambda y_{1.3}=0,829$ & $\lambda y_{2.3}=0,896$ & $\lambda x_{1.3}=0,631$ \\
$\lambda y_{1.4}=0,751$ & $\lambda y_{2.4}=0,676$ & $\lambda x_{1.4}=0,883$ \\
$\lambda y_{1.5}=0,754$ & $\lambda y_{2.5}=0,762$ & $\lambda x_{1.5}=0,891$ \\
$\lambda y_{1.6}=0,811$ & $\lambda y_{2.6}=0,772$ & $\lambda x_{1.6}=0,905$ \\
$\lambda y_{1.7}=0,749$ & $\lambda y_{2.7}=0,668$ & $\lambda x_{1.7}=0,886$ \\
\hline Pelatihan & Lingkungan Kerja & Budaya Perusahaan \\
\hline$\lambda x_{2.1}=0,705$ & $\lambda x_{3.1}=0,783$ & $\lambda x_{4.1}=0,865$ \\
$\lambda x_{2.2}=0,847$ & $\lambda x_{3.2}=0,683$ & $\lambda x_{4.2}=0,794$ \\
$\lambda x_{2.3}=0,886$ & $\lambda x_{3.3}=0,871$ & $\lambda x_{4.3}=0,720$ \\
$\lambda x_{2.4}=0,753$ & $\lambda x_{3.4}=0,901$ & $\lambda x_{4.4}=0,845$ \\
$\lambda x_{2.5}=0,886$ & $\lambda x_{3.5}=0,696$ & $\lambda x_{4.5}=0,880$ \\
\hline
\end{tabular}




\begin{tabular}{l|l|l}
$\lambda x_{2.6}=0,888$ & $\lambda x_{3.6}=0,838$ & $\lambda x_{4.6}=0,885$ \\
$\lambda x_{2.7}=0,829$ & $\lambda x_{3.7}=0,763$ & $\lambda x_{4.7}=0,804$
\end{tabular}

b. Koefisien Model Struktural

Tabel 2 Koefisien Parameter Struktural

\begin{tabular}{|c|c|}
\hline Motivasi Kerja & $\beta_{2.1}=0,818$ \\
\hline Kepemimpinan & $\gamma_{1.1}=0,301$ \\
\hline Pelatihan & $\gamma_{1.2}=0,242$ \\
\hline Lingkungan Kerja & $\gamma_{1.3}=0,228$ \\
\hline Budaya Perusahaan & $\gamma_{1.4}=0,199$ \\
\hline
\end{tabular}

\subsection{Evaluasi Model Partial Least Square}

\subsubsection{Evaluasi Model Pengukuran}

Evaluasi model pengukuran Convergent Validity, Discriminant Validity dan Composite Reliability dan Cronbach Alpha. Berdasarkan Tabel 1 masih terdapat nilai loading factor $(\lambda) \leq 0,7$ yaitu pada indikator $\lambda x_{1.3}, \lambda x_{3.2}, \lambda x_{3.5}, \lambda y_{2.1}$, $\lambda y_{2.4}$ dan $\lambda y_{2.7}$ sehingga indikator tidak digunakan dalam proses analisis (Chin, 1998). Selanjutnya untuk discriminant validity diperoleh hasil seperti pada Tabel 3.

Tabel 3 Nilai $\sqrt{\mathrm{AVE}}$ dari setiap Variabel Laten.

\begin{tabular}{|c|c|}
\hline Variabel Laten & $\sqrt{\boldsymbol{A V E}}$ \\
\hline Kinerja Pegawai & 0,660 \\
\hline Motivasi Kerja & 0,624 \\
\hline Kepemimpinan & 0,799 \\
\hline Pelatihan & 0,690 \\
\hline Lingkungan Kerja & 0,725 \\
\hline Budaya Perusahaan & 0,688 \\
\hline
\end{tabular}


Dari Tabel 3 diatas terlihat bahwa nilai $\sqrt{A V E}>0,5$, hal ini menunjukkan bahwa semua variabel laten memenuhi kriteria discriminant validity. Sedangkan dari nilai composite reliability pada Tabel 4, dapat disimpulkan bahwa semua variabel laten memiliki nilai composite reliability lebih besar dari 0,7 hal ini menunjukkan bahwa semua indikator reliabel.

Tabel 4 Nilai Composite Reliability dari setiap Variabel Laten.

\begin{tabular}{|c|c|}
\hline Variabel Laten & Composite Reliability \\
\hline Kinerja Pegawai & 0,885 \\
\hline Motivasi Kerja & 0,921 \\
\hline Kepemimpinan & 0,960 \\
\hline Pelatihan & 0,939 \\
\hline Lingkungan Kerja & 0,929 \\
\hline Budaya Perusahaan & 0,939 \\
\hline
\end{tabular}

Berdasarkan nilai cronbach alpha pada Tabel 5, semua variabel laten memiliki nilai cronbach alpha lebih besar dari 0,5 sehingga semua indikator reliabel. Nilai $R$-square sebesar 0,770 dan untuk variabel konstruk kinerja pegawai sebesar 0,660. Nilai Q-square Predictive Relevance adalah sebesar $Q^{2}=1-\left(1-R_{p}^{2}\right)=1-(1-0,770)(1-0,660)=0,921$ dan Goodness of Fit GoF $=0,9988$.

Tabel 5 Nilai Cronbach Alpha dari setiap Variabel Laten.

\begin{tabular}{|c|c|}
\hline Variabel Laten & Cronbach Alpha \\
\hline Kinerja Pegawai & 0,826 \\
\hline Motivasi Kerja & 0,899 \\
\hline Kepemimpinan & 0,950 \\
\hline Pelatihan & 0,924 \\
\hline Lingkungan Kerja & 0,904 \\
\hline Budaya Perusahaan & 0,924 \\
\hline
\end{tabular}




\subsubsection{Uji parameter}

Dengan hipotesis statistik yang digunakan $\mathrm{H}_{0}: \lambda_{\mathrm{i}}=0$ dan $\mathrm{H}_{1}: \lambda_{\mathrm{i}} \neq 0$, dan taraf signifikansi yang digunakan adalah $\alpha=5 \%$ dan $t$-tabel $=1,997$, diperoleh hasil yang disajikan pada Tabel 6 .

Tabel 6 Hasil Pengujian Variabel Laten

\begin{tabular}{|c|c|c|c|c|}
\hline Variabel Laten & Indikator & Loading & Std. Error & $t$-statistics \\
\hline \multirow{7}{*}{ Motivasi Kerja } & Y1.1 & 0,802 & 0,049 & 16,454 \\
\hline & Y1.2 & 0,829 & 0,044 & 18,893 \\
\hline & Y1.3 & 0,831 & 0,032 & 25,975 \\
\hline & Y1.4 & 0,749 & 0,044 & 17,137 \\
\hline & Y1.5 & 0,752 & 0,060 & 12,620 \\
\hline & Y1.6 & 0,812 & 0,032 & 25,267 \\
\hline & Y1.7 & 0,747 & 0,042 & 17,807 \\
\hline \multirow{4}{*}{ Kinerja Pegawai } & Y2.2 & 0,763 & 0,075 & 10,142 \\
\hline & Y2.3 & 0,901 & 0,029 & 30,665 \\
\hline & Y2.5 & 0.771 & 0.059 & 13,084 \\
\hline & Y2.6 & 0,808 & 0,040 & 20,099 \\
\hline \multirow{7}{*}{ Kepemimpinan } & X1.1 & 0,887 & 0,031 & 28,780 \\
\hline & X1.2 & 0,898 & 0,030 & 29,809 \\
\hline & X1.4 & 0,891 & 0,038 & 23,435 \\
\hline & & & & \\
\hline & $\mathrm{X} 1.5$ & 0,887 & 0,037 & 24,279 \\
\hline & X1.6 & 0,918 & 0,026 & 34,847 \\
\hline & X1.7 & 0,882 & 0,033 & 27,059 \\
\hline
\end{tabular}




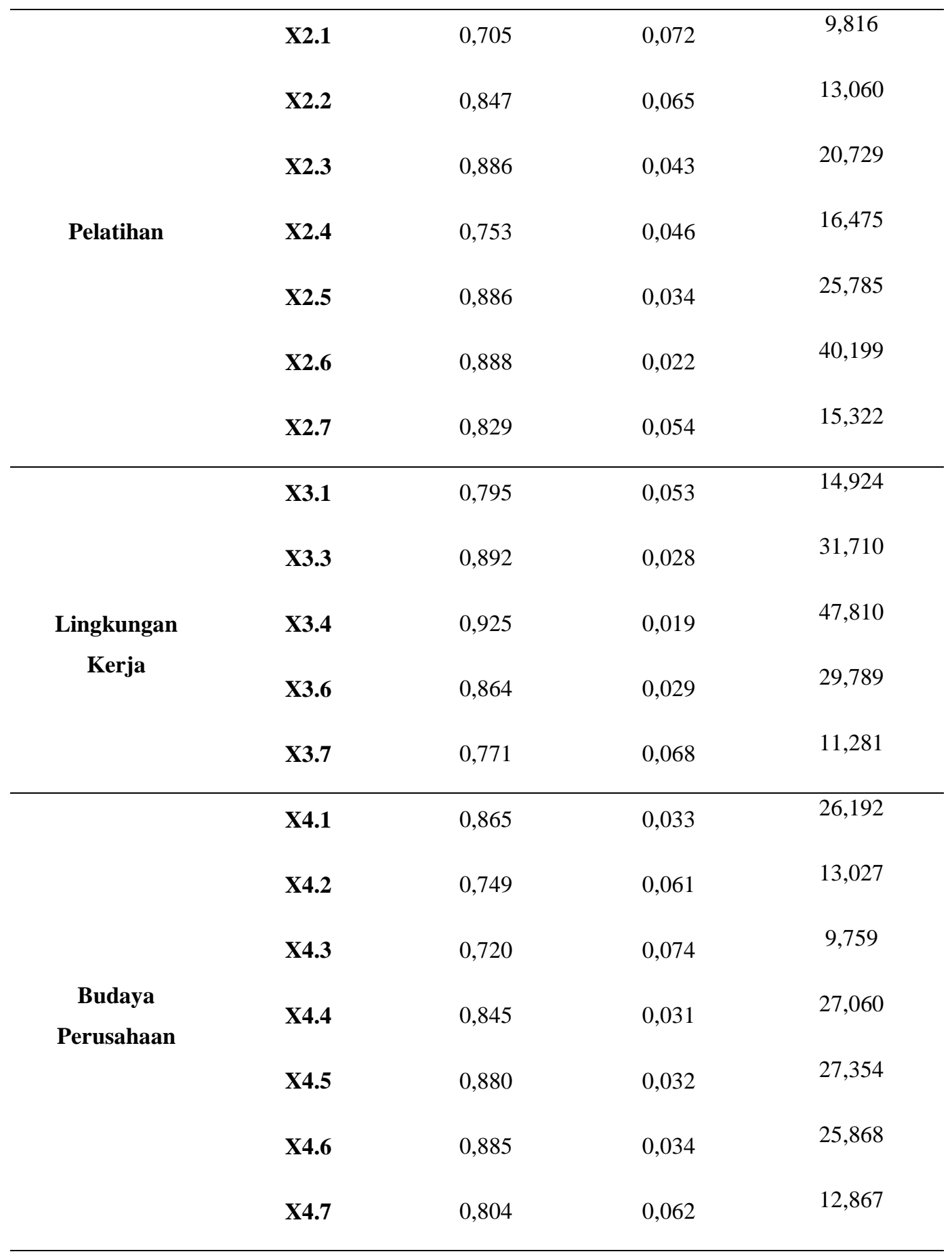

Nilai t-statistics masing-masing indikator terhadap variabel latennya lebih besar dari nilai $t$-tabel, artinya bahwa untuk semua indikator valid dan signifikan. 
Tabel 7 Pengujian $t$-statistics Resampling Bootstrap dengan Skema Path

\begin{tabular}{|l|c|c|c|c|c|}
\hline Variabel & $\begin{array}{c}\text { Original } \\
\text { Sampel }\end{array}$ & $\begin{array}{c}\text { Sampel } \\
\text { Mean }\end{array}$ & $\begin{array}{c}\text { Standard } \\
\text { Deviation }\end{array}$ & $\begin{array}{c}\text { Standard } \\
\text { Error }\end{array}$ & T Statistics \\
\hline Kepemimpinan $\Rightarrow$ Motivasi Kerja & 0,246 & 0,232 & 0,111 & 0,111 & 2,223 \\
\hline Pelatihan $\Rightarrow$ Motivasi Kerja & 0,240 & 0,217 & 0,158 & 0,158 & 1,516 \\
\hline Lingkungan Kerja $\Rightarrow$ Motivasi Kerja & 0,213 & 0,226 & 0,096 & 0,096 & 2,214 \\
\hline Budaya Perusahaan $\Rightarrow$ Motivasi Kerja & 0,297 & 0,331 & 0,133 & 0,133 & 2,228 \\
\hline Motivasi Kerja $\Rightarrow$ Kinerja Pegawai & 0,812 & 0,821 & 0,035 & 0,035 & 23,541 \\
\hline
\end{tabular}

Dengan membandingkannya nilai $\mathrm{t}$ statistics pada table 7 dengan nilai t tabel hampir semua variabel laten signifikan mempengaruhi kinerja.

\section{KESIMPULAN DAN SARAN}

Pemodelan analisis faktor-faktor yang berpengaruh terhadap kinerja pegawai di lingkungan PT. Kereta Api Indonesia (Persero) DAOP 5 Purwokerto dengan pendekatan (PLS) sudah memenuhi kriteria penilaian validitas dan reliabilitas. Model struktural dalam penelitian dengan skema path menghasilkan nilai $R$-Square sebesar 0,770 yang artinya variabel motivasi kerja yang dapat dijelaskan oleh variabel konstruk kepemimpinan, pelatihan, lingkungan kerja, dan budaya perusahaan adalah sebesar 77,00\%, sedangkan 23,00\% lainnya dijelaskan oleh variabel laten lain diluar model penelitian ini. Begitu juga variabel kinerja pegawai yang dapat dijelaskan oleh motivasi kerja adalah sebesar $66,00 \%$. Model struktural terbaik dengan skema path menggunakan pendekatan partial least square untuk pemodelan analisis faktor-faktor yang berpengaruh terhadap kinerja pegawai di lingkungan PT. Kereta Api Indonesia (Persero) DAOP 5 Purwokerto adalah:

$$
\eta_{1}=0,246 \xi_{1}+0,240 \xi_{2}+0,213 \xi_{3}+0,297 \xi_{4} ; \quad \eta_{2}=0,812 \eta_{1} .
$$

Selanjutnya, saran dari penelitian ini, diharapkan Dalam kasus ini, pemodelan PLS hanya menggunakan skema path dan estimasi yang digunakan adalah ordinary least square, sehingga pada penelitian selanjutnya dapat menggunakan skema factor dan skema centroid atau dapat dilakukan studi simulasi dengan menggunakan ketiga skema PLS untuk mengetahui karakteristik 
yang membedakan diantara ketiganya dan dapat menggunakan estimasi dengan metode singular value decomposition.

\section{DAFTAR PUSTAKA}

Abdillah, W. dan Jogiyanto. 2015, Partial Least Square (PLS) Alternatif Structural Equation Model (SEM) dalam Penelitian Bisnis, Andi, Yogyakarta, 2015.

Antaka, P. F., Pengaruh Motivasi Kerja dan Beban Kerja Terhadap Kinerja Karyawan Dipo Lokomotif dan Kereta PT. Kereta Api Indonesia (Persero) Daerah Operasi 6 Yogyakarta. Skripsi, Fakultas Ekonomi, Universitas Negeri Yogyakarta, Yogyakarta, 2018.

Bernardin, H. J. dan Russel, J. E. A., Human Resource Management, Mc GrawHill, Inc, New York, 200.

Chin, W. W., The Partial Least Squares Approach for Structural Equation Modelling. Modern Method for Business Research, Lawrence Erlbaum Associates, London, 1998.

Fruchter, B., Introduction to Factor Analysis, Nostrand Company, Ltd., New York, 1954.

Hair, J. F., Black, W. C., Babin, B. J., dan Anderson, R. E., Multivariate Data Analysis, Seventh Edition, Pearson Prentice Hall, New Jersey, 2010.

Kuntoro, H., Konsep Desain Penelitian, Universitas Airlangga, Surabaya, 2006.

Rivai, Veithzal, Fawzi, A., Basri, M., Sagala, E. J., dan Murni, S., Performance Appraisal (Sistem Yang Tepat untuk Menilai Kinerja Karyawan dan Meningkatkan Daya Saing Perusahaan), Edisi Kedua, PT. Raja Garfindo Persada, Jakarta, 2011. 